\title{
MOF-derived Porous NiO Nanorod and Microflower Structures with Enhanced Non-enzymatic Glucose Electrochemical Sensing Performance
}

\author{
Xiaobei Zhang ${ }^{1}$, Rui Wang ${ }^{2}$, Yaqing Wei ${ }^{2}$, Xiaoqi Pei ${ }^{2}$, Zhuo Zhou', Jingchao Zhang ${ }^{2}$, \\ Renchun Zhang', Daojun Zhang ${ }^{2, *}$ \\ ${ }^{1}$ College of Chemistry, Zhengzhou University, 100 Science Road, Zhengzhou 450001, P. R. China \\ ${ }^{2}$ Henan Key Laboratory of New Optoelectronic Functional Materials, College of Chemistry and \\ Chemical Engineering, Anyang Normal University, Anyang 455000, Henan, China \\ *E-mail: zhangdj0410@,sohu.com, zjc19830618@,126.com
}

doi: $10.20964 / 2021.04 .65$

Received: 5 December 2020 / Accepted: 8 February 2021 / Published: 28 February 2021

The porous and hierarchical structure with plentiful electroactive sites may ensure high activity and stability in electrocatalytic oxidation glucose by accelerating the transport of analyzer and electron during the electrochemical process. Thus, to design and fabricate electrode materials with different structures and morphology is still an appreciation method to promote electrochemical performance. In this work, two morphology of porous $\mathrm{NiO}$ structures were synthesized by the MOF-derived precursors after the calcination process. The obtained $\mathrm{NiO}$ structures prepared by thermal conversion of Ni-BTEC and Ni-PTA frameworks at mild temperature conditions not only possess the nanorods and microflowers morphology of the MOF precursors but also exhibit large surface area, which could be used as the enzyme-free catalyst for glucose electrooxidation in the basic supporting electrolyte. The result indicates that MOF-derived porous $\mathrm{NiO}$ nanorods and microflowers may be potential electrode materials for glucose electrochemical sensing.

Keywords: porous NiO structure; nanorods; microflowers; enzyme-free glucose sensor; electrocatalysts

\section{FULL TEXT}

(C) 2021 The Authors. Published by ESG (www.electrochemsci.org). This article is an open access article distributed under the terms and conditions of the Creative Commons Attribution license (http://creativecommons.org/licenses/by/4.0/). 